Running head: British Sikh identity, distinctiveness and continuity

\title{
British Sikh identity and the struggle for distinctiveness and continuity
}

\author{
Rusi Jaspal, Ph.D. \\ University of Nottingham
}

Sikhs constitute a high proportion of the ethnic minority population in Britain. Yet, social psychologists have largely neglected this demographically important religious group, leaving much of the theorising to anthropologists and sociologists. The present study explores how a group of British-born Sikhs understood and defined their Sikh identities, focussing upon strategies for safeguarding the continuity and distinctiveness of this identity. Ten individuals were interviewed. Informed by identity process theory, the transcripts were subjected to thematic analysis. Three superordinate themes are reported, namely (i) "Freedom and gender equality": the "essence' of Sikh identity; (ii) "We are the followers of Guru Nanak": continuing the legacy of the Gurus; and (iii) Maintaining group continuity and distinctiveness in a threatening social context. Theoretical and practical implications of the research are discussed, particularly in relation to intergroup relations.

Keywords: identity; religion; Sikhs; identity process theory; social representations theory

\section{Correspondence}

Dr Rusi Jaspal, Institute for Science and Society, School of Sociology and Social Policy, University of Nottingham, University Park, Nottingham NG7 2RD, United Kingdom. E-mail: rusi.jaspal@gmail.com

\section{Acknowledgements}

Sections of this paper were presented at the Punjab Research Group Meeting at Wolfson College, Oxford University on $29^{\text {th }}$ October 2011. The author would like to thank Professor Eleanor Nesbitt, Dr Arjan Bos and three anonymous reviewers for providing detailed comments on earlier versions of this paper. 


\title{
British Sikh identity and the struggle for distinctiveness and continuity
}

\author{
Rusi Jaspal, Ph.D. \\ University of Nottingham
}

Decades of Sikh migration have given rise to a substantial Sikh diaspora, with large communities across Europe, North America and the Middle East. The 2001 UK Census recorded the British Sikh population at 336,179 individuals. ${ }^{1}$ British Sikh settlement in Britain has resulted in first, second and even third generations of British-born Sikhs. There is now a growing number of theoretical and empirical studies focusing upon various forms of self-identification among British South Asians in general (e.g. Jaspal \& Cinnirella, in press; Vadher \& Barrett, 2009) and British Muslims in particular (e.g. Hopkins, 2004; Jacobson, 1997). Conversely, there is relatively less empirical research into British Sikh identity, especially from social psychologists. Much of the existing work on British Sikhs provides historical and socio-political accounts of the Sikh community in Britain (e.g. Singh \& Tatla, 2006), and does not examine the sociopsychological processes underlying the construction of Sikh identity. This paper partially addresses this lacuna in knowledge through the presentation of an empirical study of young British Sikhs' meaning-making vis-à-vis British Sikh identity. Drawing upon identity process theory (IPT) (Breakwell, 1986), the present section outlines the motivational principles, which appear to underlie the construction of British Sikh identity, and how they are protected at the socio-psychological level.

\section{The theoretical framework}

This paper explores identity construction, threat and protection. Accordingly, the study draws upon IPT, which provides an integrative theory of identity construction, threat and coping, by outlining (i) the desirable end-states for identity; (ii) social situations likely to 'threaten' identity and (iii) the strategies likely to be implemented by the individual in order to cope with the threat. Breakwell (1986, p. 24) has identified four identity principles, which 'specify the end states which are desirable for identity'. It is argued that individuals will endeavour to attain feelings of self-continuity across time (continuity); uniqueness and differentiation from relevant others (distinctiveness); competence and control over their lives and future (self-efficacy); and feelings of personal worth (self-esteem). The four identity principles can also function at the group level. For instance, Jaspal and Yampolsky (2011, p. 220) argue that, in addition to self-continuity as described above, 'individuals may derive a sense of continuity from the perceived survival of their group over time', which they refer to as 'group continuity'. Moreover, Vignoles et al. (2000) suggests that people can derive feelings of distinctiveness from perceiving their ingroup as distinctive from outgroups. IPT holds that if the individual cannot attain these principles, identity is threatened, which is aversive for psychological well-being. Accordingly, the individual will attempt to minimise threat by engaging in coping strategies (e.g. denial, outgroup derogation).

IPT acknowledges the importance of social representations in shaping how social phenomena will impact the identity principles. For Breakwell (1986, p. 55), a 'social representation is essentially a construction of reality', which enables individuals to interpret the social world and to render it meaningful (Moscovici, 1988). Social representations can make

\footnotetext{
${ }^{1} 2001$ Census, Office of National Statistics.
} 
some principles more psychologically salient than others, because they dictate what is socially and culturally important in a given context (Breakwell, 1986). For example, in a context where a group feels besieged by threatening outgroups, it is possible that group continuity will become more aroused (Bar-Tal, 1992; Jaspal \& Yampolsky, 2011). This highlights the importance of integrating IPT and social representations in the present analysis (Breakwell, 2001).

Other identity theories were examined to assess their potential 'fit' in this study. IPT was considered to be of greater heuristic value than social identity theory (SIT) (Tajfel, 1982), given the SIT focus upon distinctiveness and self-esteem. Moreover, Brewer's (1991) optimal distinctiveness theory was deemed to be less adequate than IPT, due to its primary concern with distinctiveness and belonging, with little coverage of how continuity interacts with identity. Conversely, IPT provides scope for theorising the links between multiple identity principles and for the identification of new principles. Furthermore, it successfully integrates identity threat (perception) and coping (action), as well as the intrapsychic and the intergroup levels of analysis, promising a more holistic approach.

Dominant socio-psychological theories of social identity construction highlight the universal importance of (intergroup) distinctiveness and self-esteem, in particular (Brewer, 1991; Tajfel, 1982). Moreover, the continuity principle has been described as a defining element of any identity (Wiggins, 2001). However, it is noteworthy that Jaspal and Cinnirella (in press) have argued that close attention to the qualitative nature of attachment to the social group can elucidate the principles more pertinently associated with the construction of particular identities. Similarly, it is believed that close attention to participants' accounts of their Sikh identities can elucidate the salience of particular identity principles. Furthermore, given that Sikhism can constitute a form of ethno-cultural identity for many British Sikhs (Ballard, 1994), it may be useful to draw upon theoretical strands from work on ethnic identity among British South Asians (e.g. Jaspal \& Cinnirella, in press). The following section discusses previous theory and research pertinent to the Sikh community in order to explore how the motivational principles might interact with British Sikh identity construction.

\section{Sikhism}

Sikhism was developed as a monotheistic religious ideology in fifteenth-century Punjab. It is based upon the teachings of the first Sikh Guru, Guru Nanak Dev, and was further developed by ten successive Gurus. After the death of the tenth Guru, the guruship was invested in the Sikh religious text, the Guru Granth Sahib. Drawing upon tenets of the reformist religious movements in the Punjab region, Guru Nanak Dev transcended the existing religions of Hinduism and Islam in order to create 'a new religion for a new age' (Singh \& Tatla, 2006, p. 12). Thus, the distinctiveness of Sikhism is of historical importance. (cf. Nesbitt, 2005). The Guru emphasised the centrality of the devotional, formless, omnipresent Creator in the Sikh religion. In addition to this spiritual dimension, there was an important social dimension to the new Sikh religion, focussing upon (i) social equality; (ii) the rejection of caste discrimination, which was particularly associated with Hinduism; and (iii) the centrality of seva (community service). ${ }^{2}$ Collectively, these three social tenets of Sikhism were intended to differentiate the new religion from Hinduism, in particular. However, the Muslim Mughals who ruled India during that period sought to curb the spread and expansion of Sikhism in their realm through forced conversions to Islam and other forms of persecution against the Sikhs (Mukhia, 2004). This intergroup conflict

\footnotetext{
${ }^{2}$ While the Sikh Gurus discouraged caste discrimination, caste endogamy and, thus, the structural separation of caste groups were largely taken for granted.
} 
created the persisting social representation that Sikh group continuity was threatened by the Muslim outgroup (Singh \& Tatla, 2006).

In a symbolic move to defend the Sikh religion from outgroup attacks, the final human Sikh guru, Guru Gobind Singh, baptised the Khalsa (the Pure). These baptised Sikhs consisted of five elite soldiers from the Sikh community, who were differentiated from others by five external symbols. Today, baptised Sikhs continue to wear those five symbols, the Panj Kakkar ('five Ks'), namely (i) kesh (unshorn hair worn in a turban); (ii) kangha (a small wooden comb worn in the hair); (iii) kachera (white shorts worn as underwear); (iv) kara (an iron bracelet); and (v) kirpan (a curved sword) (see McLeod, 1989). Clearly, maintenance of the 'five Ks' among baptised Sikhs renders them a physically distinctive and easily recognisable religious group. Possibly for this reason, many non-baptised Sikhs wear a turban, even if they do not wear the other four Ks. British Sikhs may employ one or more of these physical symbols, in addition to 'cultural' symbols (e.g. the liturgical language, norms, customs), in order to establish an ethnoreligious boundary around themselves (Ballard, 1994). This can enhance feelings of distinctiveness from relevant others, such as Hindus and Muslims, in particular (Tajfel, 1982; Vignoles et al., 2000).

\section{British Sikh identity}

In Britain, Sikhs have drawn social and political attention to their distinctiveness through their involvement in several public controversies (e.g. Beetham, 1970). In many respects, British Sikhs are the pioneers of British multiculturalism, having relentlessly campaigned for the right to wear the Sikh turban in the workplace and instead of a motorcycle helmet, and to carry the kirpan (the Sikh sword) in public space, for instance (Singh \& Tatla, 2006). These campaigns to protect symbols associated with Sikhism could plausibly be regarded as a means of protecting Sikh distinctiveness from other religious and ethnic groups. Indeed, the wearing of turban automatically differentiates a Sikh from Hindus, Muslims and Christians. However, the sociopolitical event which rendered the Sikhs an internationally conspicuous group was the global Sikh campaign for the establishment of an independent Sikh state, Khalistan, during the 1980s and 1990s. The violent nature of this movement ensured that Sikhism remained an identifiably distinctive religious group throughout the world (Tatla, 1999).

Despite the relative decline of the Sikh independence movement, British Sikhs have continued to mobilise socially in response to perceived threats to the integrity of Sikh identity and the Sikh public image. For instance, the play Behzti ('Dishonour'), written by Gurpreet Kaur Bhatti, explored the issues of sexual abuse, manipulation and murder within the context of a Sikh temple. Subsequent to its opening at a Birmingham theatre in December 2004, there were violent demonstrations by members of the Sikh community, which culminated in the storming of the theatre by demonstrators and the withdrawal of the play from theatres for security reasons. While hailed as a victory for 'common sense' by some British Sikhs, the event highlighted a defensive dimension of Sikhism, attracting criticism from the general public (Singh \& Tatla, 2006). From a socio-psychological perspective, it may be regarded in terms of a group mobilisation strategy for protecting group continuity, safeguarding the integrity of the religious group amid potential threats (Breakwell, 1986).

It is conceivable that meaning-making vis-à-vis Sikh identity among British Sikhs may differ from that of Sikhs elsewhere. Thus, it is important to explore the phenomenological meanings of Sikh identity for British Sikhs themselves. Accordingly, it may be useful to differentiate between religious belief and institutional practice, since these modes of expression are phenomenologically distinct. Jaspal and Coyle (2010a, p. 19) argue that 'religious identity 
might refer to a system of religious beliefs and to religious/ spiritual experience for some... whereas for others it could be akin to a form of cultural identity'. Similarly, Sikhism can constitute a religious identity corresponding to religious belief or a more cultural identity reflecting institutional practice. Sikhism manifested in cultural and institutional terms is primarily a social identity, given the general absence of a personal, spiritual relationship with God. Indeed, many young British Sikhs manifest their Sikh identity in largely cultural terms, given that, despite regular attendance at the gurdwara, most have 'only the most cursory understandings of Sikh history and theology' (Ballard, 1994, p. 114). He argues that, while some Sikhs may downgrade the religious dimension of their Sikh identities, they nonetheless derive a sense of distinctiveness from being Sikh. Thus, the maintenance and continuity of Sikh identity may in fact safeguard feelings of distinctiveness.

Given the acknowledged centrality of self-differentiation from others in social identity construction (Tajfel, 1982), it is deemed important to explore accounts of intergroup relations with other ethno-religious groups in the British context. Alexander (2000) has observed that British Pakistani and British Indian youths have engaged in gang-related conflict in some British cities, suggesting that ethnic and religious identities can be employed to mobilise these groups in conflict against one another. Indeed, Jaspal (2011) has observed in his qualitative study of ethnic and national identification among British South Asians that British Sikhs may derogate British Muslims and reproduce Islamophobic social representations partly as a means of positioning themselves rhetorically and psychologically alongside the White British majority. Furthermore, the perception that, especially since 9/11, outgroups homogenise Muslims and Sikhs may motivate British Sikhs to distance themselves from British Muslims, as a means of shielding themselves from Islamophobia (Jaspal \& Cinnirella, in press).

\section{Aims}

The literature review demonstrates the need to explore the phenomenological aspects of British Sikh identity construction, as well as the role of the motivational principles of identity therein. Accordingly, the present article investigates (i) the identity elements (or self-aspects) perceived to constitute British Sikh identity; (ii) the ways in which individuals may attain the identity principles in relation to British Sikh identity; and (iii) how British Sikhs might cope with threats to these principles.

\section{METHOD}

\section{Participants}

Ten participants were recruited from the Sikh community in Derby, England. The study focused solely upon the perceptions and experiences of British-born Sikhs. A snowball sampling strategy was employed, with the first three participants recruited from within the author's own social networks. The study was introduced as one on 'being Sikh and Asian in Britain', focusing upon both religious and ethnic identities. Of the ten participants recruited, six were male and four female. The age range of participants was 18 to 27 . Four participants were current/ former university students and the remaining six had GCSE/A-levels. All participants were of Punjabi background and self-identified as Sikhs.

\section{Procedure}

Participants were interviewed by a Punjabi-speaking non-Sikh individual of partial South Asian heritage. All participants were aware that the interviewer was neither Muslim nor Hindu and 
perhaps for this reason expressed no reservations about voicing concerns about Sikh-Muslim and Sikh-Hindu relations. Initial participants from within the interviewer's social networks were fully aware of the interviewer's ethno-religious heritage, while participants subsequently recruited using a snowball sampling strategy might have assumed that the interviewer was a Sikh due to his Sikh-sounding surname, although this was not overtly commented upon by participants. All interviews were conducted in English, although participants sometimes employed particular terms in Punjabi (e.g. 'izzat' [honour]).

Interviews were guided by a semi-structured schedule consisting of fifteen exploratory, open-ended questions. The schedule included questions regarding self-description and identity; the perceived characteristics of Sikhism; experiences of being a Sikh in Britain; the relationship between Sikhism and the principles of identity as defined in IPT; and the centrality of Sikh identity in relation to other identities. Seven participants were interviewed in their homes and the remaining three in the interviewer's home. Interviews lasted between sixty and ninety minutes. They were digitally recorded and transcribed verbatim.

\section{Analytic approach}

The data were analysed using qualitative thematic analysis as described by Braun and Clarke (2006). This approach was considered particularly useful since it allows the researcher to draw upon relevant theoretical concepts in order to add theoretical depth to the data analysis. Furthermore, this approach enables the analyst to engage with both the phenomenological and rhetorical aspects of participants' accounts, providing a more holistic account of British Sikh identity. Given the epistemological flexibility of the approach, it was deemed particularly suitable for the present study. Thematic analysis has been used in several IPT research studies (e.g. Jaspal \& Coyle, 2010b), as well as in research into social representations (e.g. Pearce \& Stockdale, 2008).

Turning to the analytic procedures, the transcripts were read repeatedly in order to become as intimate as possible with the accounts. The right margin was used to note emerging theme titles which captured the essential qualities of the accounts. Themes were constructed through the interpretive lens of IPT. This procedure was repeated with every interview transcript. Three superordinate themes representing the 10 accounts were then ordered into a logical and coherent narrative structure. It is noteworthy that this study was not intended to be empirically generalisable, but rather theoretically generalisable, given that findings are related to emerging results from other studies and there may be a degree of transferability between similar research contexts (see Smith \& Eatough, 2007)

It is noteworthy that the analyst, though not a Sikh himself, could be positioned as an 'ethnic insider' due to his common origins in the Punjab region of India, as well as his proficiency in the Punjabi language (Jaspal \& Coyle, 2010b). However, the analyst's 'outsider' status in terms of religious group affiliation allowed for a more 'naïve' and exploratory analysis, which was firmly grounded within the data generated. Indeed, constant referral to the raw data when providing analytical interpretations has been suggested as one means of optimising qualitative psychological research (Elliot et al., 1999). It was deemed important to reflect upon the relationship between previous theory and emerging insights. Theoretically, identity was conceived in terms of IPT, which was reflected in the interview schedule and in the data analysis. There was a concern with understanding the phenomenology of Sikh identity on participants' own terms, but this was related explicitly to how Sikh identity (as conceived by participants themselves) might satisfy or impinge upon the identity principles. 
In the quotations from participants that are presented in the next section, three dots indicate where material has been excised; and other material within square brackets is clarificatory.

\begin{abstract}
ANALYSIS
This section reports the following themes; (i) "Freedom and gender equality": the distinctive 'essence' of Sikhism; (ii) Continuing the legacy of the Gurus; and (iii) Maintaining group continuity and distinctiveness in a threatening social context.

\section{"Freedom and gender equality": the distinctive 'essence' of Sikhism}

A key concern in the present study was to explore the qualitative nature of British Sikh identity, focusing upon those self-aspects, which were perceived to be crucial 'markers' of this group membership. Predictably, knowledge of the Punjabi language was constructed as a necessary self-aspect:
\end{abstract}

Kiran (female): Punjabi is quite important for a Sikh to know, because it is different from Hindi which is obviously a Hindu language. 'Hindi' and 'Hindu' have the same origins.

Interviewer: Do Muslims also speak Punjabi though?

Kiran: Yeah, I suppose. They call it Punjabi but it's different than how we speak it basically. I mean, speaking our Punjabi is important for a Sikh and you can tell a Sikh from a Muslim speaking, I mean.

Jaspal and Coyle (2010a, 2010b) have argued that languages associated with one's ethnic and/ or religious identities can be employed rhetorically in order to demonstrate and legitimise one's membership in these groups. Moreover, the Punjabi language has been standardised and now has official status in the Sikh-majority state of Punjab (Nesbitt, 2000). Kiran invokes the Punjabi language as a marker of Sikh distinctiveness from Hinduism, given that she perceives an inextricable link between the linguistic category 'Hindi' and the religious category 'Hindu'. This is consistent with the SIT construct of social intergroup comparison (Tajfel, 1982).

However, the interviewer's observation that the Punjabi language is also spoken by Muslims in Pakistan prompts a strategic 're-conceptualisation' of the language. Kiran highlights the existence of varieties of Punjabi in accordance with religious group membership, which essentially delineates the 'version' of Punjabi spoken by Sikhs from that allegedly spoken by Muslims (see Jaspal and Coyle, 2010b). Thus, the Punjabi language retains its ability to construct distinctiveness since it is re-constructed as 'our [Sikh] Punjabi' vis-à-vis 'Muslim Punjabi'.

The Punjabi language can constitute a salient marker of Sikh distinctiveness, despite its association with Pakistani identity (Talbot, 2009). Similarly, the salient need for intergroup distinctiveness was compellingly exhibited by the importance attached by participants to 'unique' ideological aspects of Sikhism:

Ravinder (male): For me being a Sikh it's all about being free to do whatever you want to without any fears of persecution or being thrown out of the religion. It's basically very unorthodox unlike say Muslim religion for example. I mean in Muslim countries they'll kill you for converting to another religion for example like in Iran they'll hang you... freedom and gender equality, that's what my religion teaches. And that's a big difference from Islam and I'm really proud to be a Sikh. 
Interviewer: What parts of Sikhism make you proud?

Ravinder: Well the freedom, the equality and the uniqueness of being a Sikh. It's a beautiful religion and being part of it makes me feel like I'm part of something really different that really makes a difference.

Here, Ravinder highlights the psychosocial value of notions of 'freedom' and 'equality' in the Sikh religion, which are juxtaposed with the 'orthodoxy' and 'intolerance' of Islam. In order to construct Islam as an orthodox and intolerant religious ideology, Ravinder draws upon the social representation that Islam advocates capital punishment for apostasy. He anchors this social representation to Iran, which is known for its use of capital punishment for apostasy (Zimmermanns, 2009). The participant employs the specific example of Iran, in order to demonstrate the general intolerance and orthodoxy of Islamic religious doctrine as a whole. The juxtaposition of social representations that Sikhism is inclusive and unorthodox and that Islam is intolerant and tyrannical constitutes a form of downward comparison, whereby the ingroup is favourably compared with an outgroup (Wills, 1981). Ravinder notes that 'being part of it [the Sikh religion] makes me feel that I'm part of something that's really different'. This suggests that the individual and group levels of distinctiveness are connected in that Ravinder seems to be employing group distinctiveness in order to derive a sense of individual distinctiveness.

Participants highlighted various aspects of Sikhism, which served to accentuate social representations of Sikh distinctiveness from other religions:

Well, basically [in Sikhism] nobody goes and kills you for marrying someone of your choice like honour killings, no forced marriage and no 'men here, women there' like you get at the mosque or in Muslim weddings. It's all about fairness and the Guru's main teachings are fairness and being treated the same whatever you are. That's important to me as a woman (Manjeet, female)

Manjeet draws upon (Islamophobic) social representations regarding forced marriage, gender segregation and 'honour killings' among Muslims in general. Indeed, izzat (honour) is a powerful cultural element in both South Asian Muslim and Sikh society. There has been documented violence (including 'honour killings') in Sikh communities, although the participant distances this from Sikhism and implies that it is associated with Muslims (Jaspal \& Cinnirella, 2010). Manjeet's reproduction of these representations serves to distinguish Sikhism positively from Islam by highlighting its positive characteristics vis-à-vis the 'negativity' of Islam. This is consistent with the suggestion that individuals typically aim for positive rather than negative distinctiveness (Tajfel, 1982). The strategy of downward comparison was pervasive among participants, as exemplified in Satwinder's account of the 'essence' of Sikhism:

Satwinder (male): Sikhism is tolerance. It's essence... Say like being gay, nowhere in the Guru Granth Sahib does it say they should be executed or mistreated... It's really different from everything else.

Interviewer: How does it make you feel though being a Sikh?

Satwinder: Unique, that's for sure. That's the main reason for being a Sikh the fact that it has a unique message that's different from other religions and it's good-different, not bad-different unlike the Muslim religion. 
Participants generally invoked phenomenologically important aspects of their individual identities in order to demonstrate the 'tolerance' and 'superiority' of Sikhism. For instance, Manjeet (above) highlighted the phenomenological importance of gender equality 'as a woman'. Similarly, Satwinder, who self-identified as gay, regarded Sikhism as an accessible religious philosophy partly because of his perception of greater acceptance of homosexuality in Sikhism (than in Islam). Satwinder's later invocation of Islam suggests that the religious category Islam is in fact at the psychological forefront when thinking about institutionalised persecution of homosexuality among religious outgroups. Indeed, the social representation of Islamic intolerance of homosexuality became particularly salient in Western society following the widely publicised public executions of two young gay men in the Islamic Republic of Iran in 2005 (Kim, 2005). While participants selected distinct self-aspects of phenomenological significance in meaning-making concerning Sikhism and Islam, the basic psychological function remains the same: individuals attempt to construct Sikhism as more tolerant than Islam, thereby developing feelings of positive distinctiveness from the intergroup comparison (Tajfel, 1982).

\section{Continuing the legacy of the Gurus}

Despite the pervasive social representation of Sikh 'unorthodoxy', several participants paradoxically alluded to the need for adherence to norms and values prescribed by the Khalsa in order to maintain a sense of continuity:

It can be easy to forget what the religion teaches when you're here, because you move away from it over time so that's not good... It feels senseless to call yourself a Sikh when you're not acting like the Gurus said, as defined by the Khalsa... Yes, like you're moving away from the tradition and the background of Sikhs and that is worrying (Baljeet, male)

Jaspal and Cinnirella (in press) have argued that the continuity principle may be more pertinently associated with the construction of ethnic and religious identities, since tradition constitutes an important aspect of these forms of social attachment. Accordingly, Baljeet's desire to avoid 'moving away from tradition' and Sikh 'background' suggests that this principle may be susceptible to threat. The threat renders nominal self-identification as a Sikh as 'senseless'. Moreover, this potential 'loss' of identity is regarded as 'worrying', given that this constitutes an important self-aspect. Baljeet suggests a strategy for avoiding gradual self-distancing from the religious group, namely 'acting like the Gurus said [one should], as defined by the Khalsa'.

For Kiran, failure to adhere to Sikh teachings is coterminous with assimilation to either Hinduism or Islam, with a consequential loss of Sikh distinctiveness:

Otherwise you're just a Hindu basically or you're just a Muslim because Sikh teachings are based on both, aren't they? So you have to keep up the tradition, keep with the tradition (Kiran, female)

More specifically, the perceived similarities between Sikh, Hindu and Islamic ideologies, given the acknowledged 'basis' of Sikhism within these religious traditions, highlight the particular importance of maintaining Sikh distinctiveness from them. In short, the maintenance of specifically Sikh traditions is perceived to be essential for preserving group continuity, lest Sikh identity is 'lost': 
Like the Gurus taught that your cousins are your brothers and so tomorrow if we start marrying our cousins as an example then that's finished, we've lost our identity as Sikhs (Raman, female)

Raman implicitly draws upon the social representation that Islamic religious ideology permits marriage between cousins (Charsley, 2007). This is prohibited in Sikh religious and cultural doctrine, which advocates a strict policy of marital exogamy. This representation is invoked in order to exhibit the potential 'moral' consequences of Sikh assimilation to Islam. A change in cultural norms, leading to a complete loss of Sikh identity, could result in threats to the continuity principle. Like Raman, several participants highlighted the need to maintain a sense of distinctiveness from Islam in order to safeguard the continuity of the Sikh religion.

\section{Maintaining group continuity and distinctiveness in a threatening social context}

Having constructed a context of threat from the Muslim outgroup, some participants regarded a potential lack of distinctiveness from Muslims as jeopardising group continuity:

What I hate about being a Sikh in Britain is being taken for a Muslim, which is what White people do constantly and constantly and I'm sick of it... I'm a Sikh and if people just think I'm a Muslim then what's the point in being a Sikh. I might as well just be a Muslim isn't it? (Seema, female)

The perception of religious 'homogenisation' from the White British majority appears to threaten the distinctiveness principle. A lack of outgroup recognition for one's social identity can be conducive to perceived futility of self-identification with the Sikh religion. This account attests to the socio-psychological importance of identity 'validation' from relevant others (Swann, 2005). In short, the continuity principle requires outgroup members to acknowledge the distinctiveness of Sikh identity. At the intergroup level at least, this clearly exhibits the interrelations between the distinctiveness and continuity principles of identity; intergroup distinctiveness constitutes a psychological prerequisite for group continuity.

The need for distinctiveness from Islam, in particular, may be attributed to the prevalence of negative social representations of Islam in contemporary Britain (Field, 2007). Daljeet described the consequential 'threats' faced by Sikhs:

I think Sikhs are threatened in England basically, mainly because of racism and discrimination because people just think we're Muslims and they call us 'pakis' or whatever, like paki-bashing... but also because Muslims don't like Sikhs and they are basically taking over in England you can see it. They're in their gangs and they distribute leaflets about converting Sikh girls by getting them pregnant so Muslims are a big problem for Sikhs actually. If they had their way Sikhism wouldn't be a religion anymore (Daljeet, female)

For Daljeet, the salience of the distinctiveness principle is related to experiences of 'racism and discrimination' due to Islamophobia, since British South Asians can be 'homogenised' by outgroups. The threat is multifaceted. 'Homogenisation' with Muslims is perceived to be conducive to stigmatisation, which, since it hinders a positive self-conception, can adversely affect self-esteem. Moreover, there is a perceived risk of racially-motivated physical violence. Furthermore, Daljeet invokes the representation of 'Muslim gangs', which has been observed in both media and public discourse (Alexander, 2000). This is anchored to representations that Muslims are 'converting Sikh girls [to Islam]' and 'getting them pregnant', which depicts the 
Muslim outgroup as a threat to Sikh group continuity. Indeed, he notes that 'if they [Muslims] had their way' Sikhism would allegedly cease to exist in the intergroup setting.

Similarly, Ravinder constructed Muslim aggression against Sikhs as temporally pervasive, by drawing upon historical social representations of inter-religious relations in India:

If you look at the history it's just Islam and Sikhism fighting and forced converting to I mean forcing to convert to Islam and that's how our Gurus were killed some of them by the Mughals and we find Muslim schemes even nowadays (Ravinder, male)

Ravinder views Muslim-Sikh relations as being characterised by conflict and forced conversions to Islam. For him, the murder of Sikh Gurus seems to highlight the historical threat of Muslims against Sikhs. Crucially, these historical representations are temporally extended into the present, constructing Muslims as a temporally pervasive, persistent threat, fortifying the contemporary threat of Muslims. Several participants regarded the future of the Sikh religion as being vulnerable, due to Sikhism being a relatively 'young religion' vis-à-vis other religions.

I reckon if we want Sikhs to be a religion in the future we'll have to look out for each other because Sikhism is a young religion and it's not as secure as others maybe... I reckon there are people who would and want to like take away what we have, our identity really (Sandeep, male)

Continuity is clearly susceptible to threat, given the perceived vulnerability of the future of the Sikh religion. The notion that Sikhism is not a 'secure' religion reflects this perception of vulnerability. More specifically, Sandeep perceives an active threat to the religion from 'people who would want to like take away what we have', namely 'our' religious identity. The social representation that Muslims actively seek to alter or destroy Sikhism was pervasive within this sample of participants, suggesting that, in this case too, Muslims likely constitute the threatening outgroup. The threat to continuity functions at two levels. Firstly, the belief that one's religious group may cease to exist in the long-run seriously jeopardises group continuity, given that the perceived security of one's social group and its survival are essential for this level of continuity (Jaspal \& Yampolsky, 2011). Secondly, the prospect of any undesirable change within the selfconcept, such as perceiving a rupture between the past, present and future in relation to phenomenologically important ingroup memberships will likely threaten individual continuity.

In his account, Sandeep promotes the intergroup strategy of group mobilisation, whereby the social group mobilises collectively in order to challenge the threatening stimulus (Breakwell, 1986). This strategy may be advocated in response to threatened group continuity, given that this is regarded as jeopardising the entire group as a whole, rather than individual group members (see Jaspal, in press).

\section{DISCUSSION}

Although all of the principles described in IPT may be potentially relevant to the construction of British Sikh identity, it seems appropriate to focus specifically upon the continuity and distinctiveness principles, since the data indicate that these principles are most susceptible to threat and most fervently defended by participants. Indeed, the salience of these principles may be attributed to dominant social representations and the nature of intergroup relations between British Sikhs and other ethno-religious groups in the British context. Accordingly, this paper 
provides an empirical snapshot of how the continuity and distinctiveness principles may function in relation to British Sikh identity and how they are protected at the individual level.

\section{Social representations and identity}

The construction of British Sikh identity may differ from other forms of Sikh identity, given the prevalence of specific social representations (e.g. Sikh intolerance of the play Bezhti) and the coexistence of particular outgroups (e.g. Muslims) in the British context. Social representations are of course context-specific (Moscovici, 1988). However, close relations between the Punjab and the Punjabi Diaspora ensures continued communication and the exchange of social representations between the two contexts; this is vividly demonstrated in the British Sikhs' reproduction of social representations originating from the Punjabi context (e.g. that Muslims have always threatened Sikhs), as outlined in the introduction. More generally, this connects with theorising on diaspora and diasporic relations (Burholt, 2004). In addition to the exchange of goods, capital and peoples between 'homeland' and diaspora (Burholt, 2004), there is clearly an exchange of norms, values and theories reified within social representations. These may be tailored, elaborated and re-construed in order to respond to socio-psychological concerns in particular social contexts.

Participants drew upon a variety of representations in order to safeguard Sikh distinctiveness. The Punjabi language may be re-construed to differentiate Punjabi-speaking Sikhs from Hindi-speaking Hindus and 'Muslim-Punjabi-speaking' Muslims. However, participants also invoked ideological aspects of Sikhism, in order to positively differentiate the Sikh religious ingroup from the Muslim outgroup, in particular. Downward comparison (Wills, 1981) with Islam was achieved through the invocation of the concepts of 'freedom', 'equality' and 'tolerance', which were generally perceived to be absent from Islamic religious doctrine. In short, the reproduction of Islamophobic social representations serves to negativise Islam, while positively differentiating Sikhism from Islam. This reiterates the central assertion of IPT that social actors have agency in making strategic use of social representations to enhance identity (Breakwell, 2001). Given the resourcefulness of social actors in protecting ingroup identity, available representations may be strategically selected and reproduced with this aim. Indeed, Islamophobic representations are active in Western societies (Field, 2007). Moreover, the results of this study suggest that participants anchor phenomenologically significant aspects of Sikhism, which correspond to the individual's identity (e.g. women's rights; tolerance of homosexuality), to broader social representations of Islam (e.g. oppression of women; capital punishment for homosexuality). This anchoring process, which served to positively differentiate Sikhism from Islam, reflects the personalisation of social representations (Breakwell, 2001). There is some useful work which addresses the interface of identity and social representations (e.g. Breakwell, 2001). The present study contributes to this by demonstrating that individuals will make use of social representations (i) associated with their multiple group memberships (e.g. their Punjabi ethnic or British national group memberships); (ii) from distinct temporal points (e.g. $16^{\text {th }}$ century or 1947); (iii) which correspond to individual identity, in order to protect the principles of identity. Crucially, these representations may be deployed socially (i.e. to influence others) and/ or psychologically (i.e. to convince oneself).

\section{The relationship between distinctiveness and group continuity}

The present results suggest that the maintenance of intergroup distinctiveness, through the strict delineation of Sikhism from Islam and Hinduism, may be conducive to enhanced continuity. Jaspal (2011) has argued that outgroup 'homogenisation' of British South Asians may be 
threatening for identity, given the need for internal and external 'validation' of one's distinctive social identity (see also Swann, 20050. Moreover, the prevalence of Islamophobic representations means that 'homogenisation' may jeopardise both distinctiveness and (group) esteem. In short, participants lamented being 'homogenised' with Muslims and, thus, being regarded unfavourably by the White British majority. Moreover, the perceived malevolence of Muslims potentially threatens the group and individual levels of the continuity principle in relation to Sikh identity. The perceived risk of assimilation to Islamic norms and values can be similarly threatening, given that, in the minds of some participants, Sikhism may thereby cease to exist as a distinctive, collective entity. Consequently, some participants proposed closer adherence to the Guru's norms and values in order to protect Sikh distinctiveness and continuity. Perceived threats to group continuity can result in cultural 'fossilisation', whereby a more 'orthodox' and regressive version of the group's norms and values is advocated by group members (Maira, 2002). In short, the perceived 'vulnerability' of Sikhism vis-à-vis other religious groups could potentially induce a more orthodox version of Sikhism, potentially contradicting those self-aspects of Sikhism (i.e. 'tolerance', 'equality' and 'freedom') initially thought to differentiate the religion from others. On a theoretical level, these findings elucidate a potential relationship between the distinctiveness and continuity principles at the intergroup level of human interdependence. This addresses an important lacuna in IPT concerning the interrelations between the motivational principles of identity (Breakwell, 1986). It is possible that a given principle (e.g. distinctiveness) may transiently acquire salience at the psychological level in order to enhance another prioritised principle (e.g. group continuity).

\section{Conclusion}

These results are not empirically generalisable due to the small sample size. Therefore, it is hoped that future research will engage with some of these issues using more generalisable quantitative methods. However, the study does offer some important practical and theoretical insights. It is the first empirical study to elucidate how social representations (associated with distinct group memberships and temporal points) can impinge upon the construction of contemporary British Sikh identity and how this might affect intergroup relations with relevant outgroups (e.g. Muslims). On a practical level, the improvement of intergroup relations between majority and minority groups should be encouraged, but it is equally as important to facilitate and encourage an atmosphere of mutual understanding between the various minority ethnic and religious groups in British and other societies. It is easy to overlook the potential sociopsychological impact of conflict between minority groups. This paper highlights the possibility that, if ignored, intergroup relations between ethnic and religious minority groups in Britain could deteriorate, with profoundly negative outcomes for social cohesion.

\section{REFERENCES}

Alexander, C. (2000). The Asian Gang: Ethnicity, Identity, Masculinity. Oxford: Berghahn Books.

Ballard, R. (1994). Differentiation and disjunction among the Sikhs. In R. Ballard (Ed.), Desh Pardesh: The South Asian Experience in Britain. London: C. Hurst \& Co. Bar-Tal, D. \& Antebi, D. (1992). Siege mentality in Israel. International Journal of Intercultural Relations, 16, 251-75.

Beetham, D. (1970). Transport and Turbans: A Comparative Study in Local Politics. London: Oxford University Press. 
Braun, V. \& Clarke, V. (2006). Using thematic analysis in psychology. Qualitative Research in Psychology, 3, 77-101.

Breakwell, G. M. (1986). Coping with Threatened Identities. London: Methuen.

Breakwell, G.M. (2001). Social representational constraints upon identity processes. In K. Deaux \& G. Philogene (eds.), Representations of the Social: Bridging Theoretical Traditions. Oxford: Blackwell.

Brewer, M.B. (1991). The social self: on being the same and different at the same time.

Personality and Social Psychology Bulletin, 17, 475-82.

Burholt, V. (2004). Transnationalism, economic transfers and families' ties: Intercontinental contacts of older Gujaratis, Punjabis and Sylhetis in Birmingham with families abroad. Ethnic and Racial Studies, 27, 800-29.

Charsley, K. (2007). Risk, trust, gender and transnational cousin marriage among British Pakistanis. Ethnic and Racial Studies, 30,1117-31.

Elliot, R., Fischer, C.T. \& Rennie, D.L. (1999). Evolving guidelines for publication of qualitative research studies in psychology and related fields. British Journal of Clinical Psychology, 38, 215-29.

Field, C.D. (2007). Islamophobia in contemporary Britain: the evidence of the opinion polls, 1988-2006. Islam and Christian-Muslim Relations, 18, 447-77.

Hopkins, P. E. (2004). Young Muslim men in Scotland: Inclusions and exclusions. Children's Geographies, 2, 257-72.

Jacobson, J. (1997). Religion and ethnicity: Dual and alternative sources of identity among young British Pakistanis. Ethnic and Racial Studies, 20, 238-56.

Jaspal, R. (in press). Anti-Semitism and anti-Zionism in Iran: the role of identity processes. Israel Affairs.

Jaspal, R. (2011). The Construction and Management of National and Ethnic Identities among British South Asians: An Identity Process Theory Approach. Unpublished PhD dissertation, University of London, UK.

Jaspal, R. \& Cinnirella, M. (in press). The construction of ethnic identity: insights from identity process theory. Ethnicities.

Jaspal, R. \& Cinnirella, M. (2010). Media representations of British Muslims and hybridised threats to identity. Contemporary Islam: Dynamics of Muslim Life, 4, 289310 .

Jaspal, R. \& Coyle, A. (2010a). 'Arabic is the language of the Muslims - that's how it was supposed to be': exploring language and religious identity through reflective accounts from young British-born South Asians. Mental Health, Religion and Culture, 13, 17-36.

Jaspal, R. \& Coyle, A. (2010b). 'My language, my people': language and ethnic identity among British-born South Asians. South Asian Diaspora, 2, 201-18.

Jaspal, R. \& Yampolsky, M. (2011). Social representations of the Holocaust and Jewish Israeli identity construction: insights from identity process theory. Social Identities, 17, 201-24.

Kim, R. (2005). Witnesses to an execution. The Nation Online, $7^{\text {th }}$ August. Accessed from: http://www.asylumlaw.org/docs/sexualminorities/Iran080705.pdf [accessed 20 March 2011]. McLeod, W.H. (1989). The Sikhs: History, Religion and Society. New York: Columbia University Press.

Maira, S. M. (2002). Desis in the House: Indian American Youth Culture in New York City. Philadelphia: Temple University Press. 
Moscovici, S. (1988). Notes towards a description of social representations. European Journal of Social Psychology, 18, 211-50.

Mukhia, H. (2004). The Mughals. Oxford: Blackwell.

Nesbitt, E. (2000). The Religious Lives of Sikh Children: A Coventry Based Study. Leeds:

Community Religions Project, Department of Theology and Religious Studies, University of

Leeds.

Nesbitt, E. (2005) Sikhism: A Very Short Introduction. Oxford: Oxford University Press.

Pearce, J. \& Stockdale, J.E. (2008). Responses to the asylum issue: A comparison of lay and expert views. Journal of Community and Applied Social Psychology, 19, 142-155.

Singh, G. \& Tatla, D.S. (2006). Sikhs in Britain: The Making of a Community. London: Zed

Books.

Smith, J.A. \& Eatough, V. (2007). Interpretative phenomenological analysis. In E. Lyons \& A. Coyle (eds.), Analysing Qualitative Data in Psychology. London: Sage.

Swann, W.B. (2005). The self and identity negotiation. Interaction Studies, 6, 69-83.

Tajfel, H. (1982). Social psychology of intergroup relations. Annual Review of Psychology, 33, 1-39.

Talbot, I. (2009). Pakistan: A Modern History. London: C. Hurst \& Co Publishers.

Tatla, D.S. (1999). The Sikh Diaspora: The Search for Statehood. London: UCL Press.

Vadher, K. \& Barrett, M. (2009). Boundaries of British in British Indian and Pakistani young

adults. Journal of Community and Applied Social Psychology, 19, 442-58.

Vignoles, V. L., Chryssochoou, X. \& Breakwell, G. M. (2000). The distinctiveness principle:

identity, meaning and the bounds of cultural relativity. Personality and Social Psychology

Review, 4, 337-54.

Wiggins, D. (2001). Sameness and Substance Renewed. Cambridge: Cambridge University Press.

Wills, T.A. (1981). Downward comparison principles in social psychology. Psychological Bulletin, 90, 245-71.

Zimmermanns, T. (2009). Germany's asylum policy and Iran's new apostasy law. International Journal for Religious Freedom, 2, 133-39. 